\title{
Depression and Its Associated Factors among Diabetes Mellitus Patients Attending Selected Hospitals in Southwest Ethiopia: A Cross-Sectional Study
}

\author{
Adane Asefa $\left(\mathbb{D},{ }^{1}\right.$ Ameha Zewudie $\mathbb{D}^{2},{ }^{2}$ Andualem Henok, ${ }^{1}$ Yitagesu Mamo $\mathbb{D}^{2}$, \\ and Tadesse Nigussie $\mathbb{D}^{1}$ \\ ${ }^{1}$ Department of Public Health, College of Health Science, Mizan-Tepi University, Mizan-Aman, Ethiopia \\ ${ }^{2}$ Department of Pharmacy, College of Health Science, Mizan-Tepi University, Mizan-Aman, Ethiopia \\ Correspondence should be addressed to Adane Asefa; adane779@gmail.com
}

Received 26 November 2019; Revised 7 March 2020; Accepted 31 March 2020; Published 13 April 2020

Academic Editor: Joan Busner

Copyright (C) 2020 Adane Asefa et al. This is an open access article distributed under the Creative Commons Attribution License, which permits unrestricted use, distribution, and reproduction in any medium, provided the original work is properly cited.

\begin{abstract}
Background. Diabetes mellitus and depression are very common diseases worldwide, and the prevalence rates of both conditions are increasing rapidly. Depression among patients with diabetes mellitus results in poor glycemic control through different mechanisms. Besides, the coexistence of a chronic medical illness with depression reduces the probability of recognizing and treating depression. The study is aimed at assessing the prevalence and factors associated with depression among adults with diabetes mellitus. Methods. A hospital-based cross-sectional study was conducted among adult diabetes mellitus patients on follow-up in Mizan-Tepi University Teaching Hospital and Tepi General Hospital. A consecutive sampling technique was employed to recruit the study participants, and data were collected through face-to-face interview and medical chart review. Depression was measured using Patient Health Questionnaire-nine (PHQ-9). Binary logistic regression analysis was done and a $p$ value of less than 0.05 was used as a level of significance. Results. The prevalence of depression among study participants was $37.0 \%$ (95\% CI 32.0\%-42.0\%). The majority (44.7\%) of the patients had mild depression, while only $2 \%$ had severe depression. Being male $(\mathrm{AOR}=1.92,95 \% \mathrm{CI}: 1.15-3.22)$, urban residence $(\mathrm{AOR}=3.02,95 \% \mathrm{CI}: 1.57-5.78)$, single marital status $(\mathrm{AOR}=7.72,95 \% \mathrm{CI}: 3.6-16.53)$, duration of diabetes mellitus 5 years and more $(\mathrm{AOR}=2.00,95 \% \mathrm{CI}: 1.21-3.5)$, and having sexual dysfunction $(A O R=3.55,95 \%$ CI: 2.13-5.91) were associated with increased odds of depression among diabetes mellitus patients. Conclusions. The prevalence of depression among diabetes mellitus was high. Therefore, the patients should be thoroughly screened for this comorbid condition, and the significant factors should be addressed during routine follow-up.
\end{abstract}

\section{Introduction}

Diabetes mellitus (DM) and depression are major global public health problems, and the prevalence rates of both conditions are increasing rapidly $[1,2]$. It was estimated that in 2019 , there are about 463 million patients with DM worldwide, and the figure is predicted to rise to 700 million by 2045 [3]. In 2017, approximately 5 million deaths among the age of 20-99 years were due to diabetes [4]. Also, a study reported that four out of five people in the world with diabetes live in low- and middle-income countries, and these countries are facing a double burden of diabetes and infec- tious diseases [5]. Depression is also the leading cause of mental health-related diseases and a major contributor to the overall global burden of diseases [6, 7]. At a global level, over 300 million people were estimated to suffer from depression in 2015, which was equivalent to $4.4 \%$ of the world's population [8]. The number of new cases of depression increased from 17.2 million in 1990 to 25.8 million in 2017 [9]. Over 9.5 million of global depression cases are attributable to diabetes [10]. The occurrence of depression in people with diabetes mellitus is about two to three times higher compared to the general population [11-13]. Studies have reported varying results on the prevalence of depression in 
diabetes patients that ranges from $5.9 \%$ to $87 \%$ [14-19]. Researchers have argued that diabetes and depression have a bidirectional relationship; depression increases the risk of developing diabetes mellitus and vice versa [20-22].

Depression causes severe health, social, and economic consequences in patients with diabetes mellitus. It negatively affects the course of DM through hormonal, neuronal, or immune system changes that directly affect the body's ability to produce or use insulin [23]. The coexistence of depression with DM also results in poor glycemic control by causing poor self-care behaviors such as lack of physical activity [24], poor adherent to low-glucose diet and medication [25], and substance use [9, 23]. Moreover, comorbid depression in DM patients is associated with anxiety, low quality of life [26], functional impairments, increased healthcare use and cost [25], increased disability, and a higher risk of death [1]. On the other hand, the course of depression in patients with diabetes is chronic and severe; even with successful treatment, up to $80 \%$ of patients with diabetes experience depression relapse [11]. Despite all these health, social, and economic implications, depression remains unrecognized and untreated in insignificant proportions of patients with diabetes [27]. Healthcare providers may not look beyond a chronic medical illness to explain nonspecific symptoms, such as fatigue or poor concentration [9].

Evidence from literature shows that the magnitude of depression and its risk factors varied across study areas, study designs, study populations, time frames, and measurement methods in previous studies [26, 28-31]. Thus, it is difficult to precisely measure the potential public health burdens and the medical care of depression in the diabetic population. Thus, an array of studies in different settings is very important. Therefore, this study is aimed at assessing the prevalence of depression and the factors associated with DM patients in Southwest Ethiopia.

\section{Methods}

2.1. Study Setting and Period. The study was conducted at Mizan-Tepi University Teaching Hospital (MTUTH) and Tepi General Hospital (TGH) from July 01-31, 2018, among diabetes patients. The hospitals are located in Southern Nations Nationalities and People Regional State, Southwest Ethiopia. MTUTH is found in the Mizan Aman town and provides various health services for the population that comes from its catchment area (Bench-Sheko, West-Omo, some parts of the Sheka and Kafa zones, and Gambella regional state). TGH is located in Tepi town, and it offers health services for people that come from Shaka, some parts of the Kafa and Majang zones.

2.2. Study Design. A hospital-based cross-sectional study was done among adult diabetes patients on follow-up.

2.3. Population. The source population for the study was all adult patients with diabetes who had been on antidiabetic medication at MTUTH and TGH. Those adult diabetes patients who came for follow-up treatment during data collection time and recruited for interviews were the study population.

2.4. Inclusion and Exclusion. Diabetic patients aged 18 years or greater who had been on antidiabetic medication were included in the study, whereas patients who were severely sick, unable to communicate, and patients with known mental disorders were excluded from the study.

2.5. Sample Size Determination and Sampling Procedure. The sample size was calculated using a formula for a single population proportion based on the assumption of $50 \%$ prevalence of sexual dysfunction, with a 5\% margin of error and a $95 \%$ confidence interval. After adding a $10 \%$ contingency for nonresponse, the total sample size was calculated to be 423 patients. The sample was allocated proportionally to the facilities based on the total number of patients on follow-up at each facility. The patients on follow-up were identified using the medical registry book. Finally, the study participants were recruited consecutively based on their arrival at the Hospitals.

2.6. Variables of the Study. The outcome variable was depression. The predictor variables were sociodemographic factors (age, sex, religion, marital status, educational status, ethnicity, and residence), medical-related factors (types of DM, duration of DM, blood glucose, sexual dysfunction, and complications or comorbidities), and behavioral-related factors (physical activity, adherence to antidiabetic medication, and substance use).

2.7. Measurements. Data were collected using a structured questionnaire through interviewer-administered and record review methods. The tool was adapted from related literature $[32,33]$ and tailored to the local context. The tool was translated to a local language, "Amharic," then back to English, to ensure its consistency. Individuals who were proficient in both languages did the translation. Independent translators did the forward and backward translations, and the expert panel resolved the discrepancy between a forward translation and the original questionnaire. The tool was pretested on $5 \%$ of the sample size before the actual data collection and modified accordingly.

Depression was assessed based on the patient's self-reported symptoms of depression within the past fourteen days of the survey using Patient Health Questionnaire-Nine (PHQ-9). The PHQ-9 has nine items that are answered on a four-point scale $(0=$ not at all, $1=$ various days, $2=$ more than half of the days, and 3 =nearly every day). The scores were summed, and the total score was categorized into $0-4,5-9,10-14,15-19$, and 20-27 to indicate no or minimal depression, mild depression, moderate depression, moderately severe depression, and severe depression, respectively. The overall score greater than or equal to 10 indicates the presence of depression [33].

Sexual dysfunction was evaluated by Change in Sexual Function Questionnaire (CSFQ-14), which has 14 items that are answered on five-point Likert scales. The responses were summed, and the total scores of 47 and below for males and 41 and below for females indicate the presence of sexual dysfunction [32]. The serum glucose level was measured using more recent fasting blood sugar (FBS) measurements over the past three months. The average three months FBS level $\leq 130 \mathrm{mg} / \mathrm{dL}$ was considered good glycemic control, whereas $>130 \mathrm{mg} / \mathrm{dL}$ was classified as poor glycemic control. Data related to complications or comorbidities were reviewed from the medical records. Conditions such as 
TABLE 1: Sociodemographic characteristics of DM patients on follow-up in MTUTH and TGH, Southwest Ethiopia, July 2018 ( $n=398$ ).

\begin{tabular}{|c|c|c|c|c|}
\hline \multirow{2}{*}{ Variables } & \multirow{2}{*}{$N(\%)$} & \multicolumn{2}{|c|}{ Depression } & \multirow{2}{*}{$\begin{array}{l}\chi^{2} \text { test } \\
p \text { value }\end{array}$} \\
\hline & & Yes (\%) & No (\%) & \\
\hline \multicolumn{5}{|l|}{ Age } \\
\hline $18-30$ & $54(13.6)$ & $24(44.4)$ & $30(55.6)$ & \multirow{4}{*}{0.11} \\
\hline $31-40$ & $117(29.4)$ & $37(31.6)$ & $80(68.4)$ & \\
\hline $41-50$ & $160(40.2)$ & $51(31.9)$ & $109(68.1)$ & \\
\hline $51+$ & $67(16.8)$ & $35(52.2)$ & $32(47.8)$ & \\
\hline \multicolumn{5}{|l|}{ Sex } \\
\hline Male & $256(64.3)$ & $102(39.8)$ & $154(60.2)$ & \multirow[t]{2}{*}{0.10} \\
\hline Female & $142(35.7)$ & $45(31.7)$ & $97(68.3)$ & \\
\hline \multicolumn{5}{|l|}{ Religion } \\
\hline Orthodox & $136(34.2)$ & $47(34.6)$ & $89(65.4)$ & \multirow{4}{*}{0.22} \\
\hline Protestants & $141(35.4)$ & $49(34.8)$ & $92(65.2)$ & \\
\hline Muslim & $96(24.1)$ & $37(38.5)$ & $59(61.5)$ & \\
\hline Others & $25(6.3)$ & $14(56.0)$ & $11(44.0)$ & \\
\hline \multicolumn{5}{|l|}{ Marital status } \\
\hline Married & $263(66.1)$ & $73(27.8)$ & $190(72.2)$ & \multirow{3}{*}{$<0.001$} \\
\hline Single & $49(12.3)$ & $34(69.4)$ & $15(30.6)$ & \\
\hline Divorced/widowed & $86(21.6)$ & $40(46.5)$ & $46(53.5)$ & \\
\hline \multicolumn{5}{|l|}{ Ethnicity } \\
\hline Kaficho & $106(26.6)$ & $55(51.9)$ & $51(48.1)$ & \multirow{5}{*}{0.001} \\
\hline Amhara & $101(25.4)$ & $36(35.6)$ & $65(64.4)$ & \\
\hline Bench & $60(15.1)$ & $18(30.0)$ & $42(70.0)$ & \\
\hline Shakacho & $50(12.6)$ & $9(18.0)$ & $41(82.0)$ & \\
\hline Others & $80(20.1)$ & $29(35.8)$ & $52(64.2)$ & \\
\hline \multicolumn{5}{|l|}{ Educational status } \\
\hline No education & $106(26.6)$ & $36(34.0)$ & $70(66.0)$ & \multirow{3}{*}{0.090} \\
\hline Primary & $120(30.2)$ & $54(45.0)$ & $66(55)$ & \\
\hline Secondary and above & $172(43.2)$ & $57(33.1)$ & $115(66.9)$ & \\
\hline \multicolumn{5}{|l|}{ Residence } \\
\hline Urban & $284(71.4)$ & $118(41.5)$ & $166(58.5)$ & \multirow[t]{2}{*}{0.003} \\
\hline Rural & $114(28.6)$ & $29(25.4)$ & $85(74.6)$ & \\
\hline
\end{tabular}

nephropathy, retinopathy, diabetic neuropathy, diabetic foot ulcer, cardiac disease, and hypertension were considered complications or comorbidities.

Physical exercise is an engagement in moderate exercise such as slow walking or dancing to vigorous intensity exercise like fast walking or running for at least 2 days per week. We measured adherence to antidiabetic medication in the past seven days of the survey, and respondents were considered adherent if they took all antidiabetic medication as per the prescription of a physician. Substance use was measured based on respondents' self-reports on the consumption of alcohols (beer, wine, and local alcohols like 'Areke' and 'Tej'), tobacco, and Khat in any amount and frequency in the past 12 months.

2.8. Data Processing and Analysis. Data were entered into Epi data version 3.1 and exported to SPSS version 21 for analysis. Descriptive statistics were done for different variables. Bivariate binary logistic regression analyses were done, and variables that had a $p$ value less than 0.20 were entered into the multivariable model. Finally, multivariable binary logistic regression analysis was performed using the backward variable selection technique. In the last model, a $p$ value of $<0.05$ was considered the level of significance and two-tail tests were used. Model fitness was evaluated using the Hosmer-Lemeshow test, and multicollinearity was checked by the variance inflation factor (VIF).

\section{Results}

3.1. Sociodemographic Characteristics. Of the total 423 patients planned for the interview, 398 were successfully addressed making a response rate of $94 \%$. The mean age of the respondents was 41.76 (9.00) years. One hundred sixty (40.20\%) were between 41 and 50 years of age, and nearly two-thirds $(64.3 \%)$ of the respondents were male. Protestant Christians accounted for about one-third (35.4\%) of the study participants. Out of the total study participants, only $12.3 \%$ were single. About $43.2 \%$ had attended secondary school or above. The majority of the study participants (71.4\%) were urban residents. The prevalence of depression 
TABLE 2: Behavioral and medical-related factors of diabetes patients on follow-up in MTUTH and TGH, Southwest Ethiopia, July 2018 $(n=398)$.

\begin{tabular}{|c|c|c|c|c|}
\hline \multirow{2}{*}{ Variables } & \multirow{2}{*}{$N(\%)$} & \multicolumn{2}{|c|}{ Depression } & \multirow{2}{*}{$\begin{array}{l}\chi^{2} \text { test } \\
p \text { value }\end{array}$} \\
\hline & & Yes $(\%)$ & No $(\%)$ & \\
\hline \multicolumn{5}{|c|}{ Type of DM } \\
\hline T1DM & $80(20.1)$ & $26(32.5)$ & $54(67.5)$ & \multirow[t]{2}{*}{0.358} \\
\hline T2DM & $318(79.9)$ & $121(38.1)$ & $197(61.9)$ & \\
\hline \multicolumn{5}{|c|}{ Duration of DM } \\
\hline$<5$ years & $299(75.1)$ & $102(34.1)$ & $197(65.9)$ & \multirow[t]{2}{*}{0.043} \\
\hline$\geq 5$ years & $99(24.9)$ & $45(45.5)$ & $54(54.5)$ & \\
\hline \multicolumn{5}{|c|}{ Glycemic control } \\
\hline Poor & $350(87.9)$ & $18(37.5)$ & $30(62.5)$ & \multirow[t]{2}{*}{0.931} \\
\hline Good & $48(12.1)$ & $129(36.9)$ & $221(63.1)$ & \\
\hline \multicolumn{5}{|c|}{ Complication or comorbidity } \\
\hline Yes & $212(53.3)$ & $87(41.0)$ & $125(590)$ & \multirow[t]{2}{*}{0.07} \\
\hline No & $60(32.3)$ & $60(32.3)$ & $126(67.7)$ & \\
\hline \multicolumn{5}{|c|}{ Sexual dysfunction } \\
\hline Yes & $212(53.3)$ & $102(48.1)$ & $110(51.9)$ & \multirow[t]{2}{*}{$<0.001$} \\
\hline No & $186(46.7)$ & $45(24.2)$ & $141(75.8)$ & \\
\hline \multicolumn{5}{|c|}{ Substance use } \\
\hline Yes & $158(39.7)$ & $58(36.7)$ & $100(63.3)$ & \multirow[t]{2}{*}{0.94} \\
\hline No & $240(61.3)$ & $89(37.1)$ & $151(62.9)$ & \\
\hline \multicolumn{5}{|c|}{ Physical activity } \\
\hline Yes & $269(67.6)$ & $102(37.9)$ & $167(62.1)$ & \multirow[t]{2}{*}{0.557} \\
\hline No & $129(32.4)$ & 45 (34.9) & $84(65.1)$ & \\
\hline
\end{tabular}

Poor: FBS $>130 \mathrm{mg} / \mathrm{dL}$, Good: $\mathrm{FBS} \leq 130 \mathrm{mg} / \mathrm{dL}$. Complications or comorbidity (nephropathy, retinopathy, diabetic neuropathy, diabetic foot ulcer, cardiac disease and/or hypertension).

was $39.8 \%$ among males and $31.7 \%$ among females $(p=0.1)$. The singles had a higher prevalence of depression $(69.4 \%)$ compared to married (27.8\%) and divorced/widowed $(46.5 \%)(p$ value $<0.001)$. Urban residents also had a higher prevalence of depression than rural residents $(41.5 \%$ vs. $25.4 \%, p$ value $=0.003)($ Table 1$)$.

3.2. Behavioral and Medical-Related Factors. Of the total study participants, $79.9 \%$ were type 2 DM patients. The majority $(87.9 \%)$ of the patients were in a poorly controlled glycemic range (FBS $>130 \mathrm{mg} / \mathrm{dL})$. About $75 \%$ of the patients had been on antidiabetic medication for less than five years. Moreover, $39 \%$ of the patients had complications/comorbidities related to DM. More than two-thirds (67.6\%) of the study participants were engaged in regular physical exercise. One hundred fiftyeight (39.7\%) respondents had used substances in the past 12 months. More than half of the study participants $(53.3 \%)$ had sexual dysfunction. The prevalence of depression was higher among patients with complications ( $41 \%$ vs. $32.3 \%$, $p<0.001)$. Patients with sexual dysfunction had a higher prevalence of depression compared to those with no sexual dysfunction $(48.1 \%$ vs. $24.2 \%$, $p$ value $<0.001)$ (Table 2$)$.

3.3. Prevalence of Depression. The prevalence of depression among study participants was 37\% ( $n=398$, 95\% CI: $32 \%$, $42 \%)$. The majority (44.7\%) of the patients experienced mild

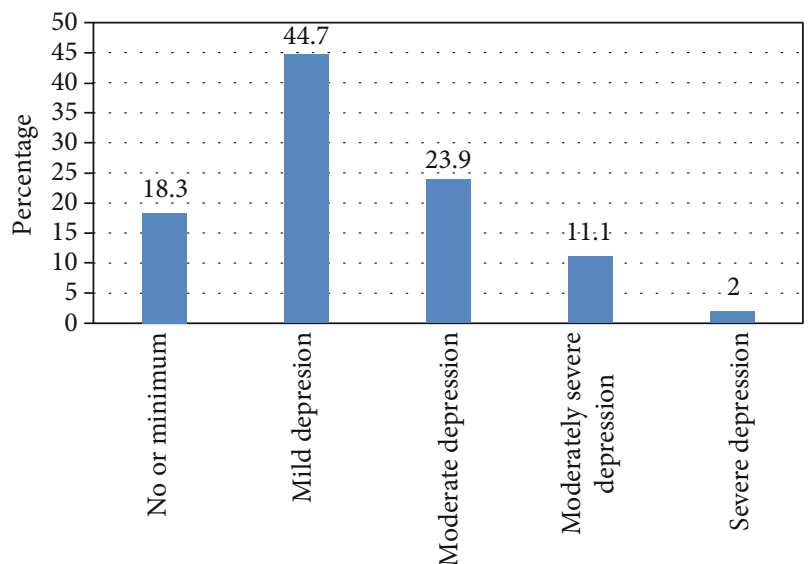

Figure 1: Prevalence of depression among DM patients in MTUTH and TGH, Southwest Ethiopia, July $2018(n=398)$.

depression, and very few (2\%) had severe depression (Figure 1).

3.4. Factors Associated with Depression among DM Patients. During a bivariate binary logistic regression analysis, age, sex, marital status, ethnicity, educational status, residence, duration of DM, complication/comorbidities, and sexual dysfunction were found to have a $p$ value less than 0.20 ; 
TABLE 3: Factors associated with depression among DM patients on follow-up at MTUTH and TGH, Southwest Ethiopia, July 2018.

\begin{tabular}{|c|c|c|c|c|}
\hline \multirow{2}{*}{ Variables } & \multicolumn{2}{|c|}{ Depression } & \multirow{2}{*}{ COR $(95 \% \mathrm{CI})$} & \multirow{2}{*}{$\operatorname{AOR}(95 \% \mathrm{CI})$} \\
\hline & Yes $(\%)$ & No $(\%)$ & & \\
\hline \multicolumn{5}{|l|}{ Sex } \\
\hline Male & $102(39.8)$ & $154(60.2)$ & $1.43(0.93-2.20)$ & $1.92(1.15-3.22)^{*}$ \\
\hline Female & $45(32.0)$ & $97(68.0)$ & 1 & \\
\hline \multicolumn{5}{|l|}{ Educational status } \\
\hline No education & $36(34.0)$ & $70(66.0)$ & $1.04(0.62-1.73)$ & $1.59(0-0.82-3.12)$ \\
\hline Primary & $54(45.0)$ & $66(55.0)$ & $1.65(1.02-2.67)$ & $0.73(0.39-1.35)$ \\
\hline Secondary and above & $57(33.0)$ & $115(67.0)$ & 1 & \\
\hline \multicolumn{5}{|l|}{ Age group } \\
\hline$<41$ & $66(35.9)$ & $118(64.1)$ & 1 & 1 \\
\hline$\geq 41$ & $81(37.9)$ & $133(62.1)$ & $1.09(0.72-1.64)$ & $0.66(0.39-1.12)$ \\
\hline \multicolumn{5}{|l|}{ Residence } \\
\hline Urban & $118(41.5)$ & $166(58.5)$ & $2.08(1.29-3.38)$ & $3.02(1.57-5.78)^{*}$ \\
\hline Rural & $29(25.4)$ & $85(74.6)$ & & 1 \\
\hline \multicolumn{5}{|l|}{ Marital status } \\
\hline Married & $73(27.8)$ & $190(72.2)$ & 1 & 1 \\
\hline Single & $34(69.4)$ & $15(30.6)$ & $5.90(3.04-11.47)$ & $7.72(3.60-16.53)^{*}$ \\
\hline Widowed and divorced & $40(46.5)$ & $46(55.5)$ & $2.26(1.37-3.74)$ & $1.91(1.0-3.47)$ \\
\hline \multicolumn{5}{|l|}{ Duration of DM } \\
\hline$<5$ years & $102(34.1)$ & $197(65.9)$ & 1 & \\
\hline$\geq 5$ years & $45(45.5)$ & $54(54.5)$ & $1.61(1.01-2.56)$ & $2.05(1.21-3.50)^{*}$ \\
\hline \multicolumn{5}{|l|}{ Sexual dysfunction } \\
\hline Yes & $102(48.1)$ & $110(51.9)$ & $2.51(1.89-4.47)$ & $3.55(2.13-5.91)^{*}$ \\
\hline No & $45(24.2)$ & $141(75.8)$ & 1 & 1 \\
\hline
\end{tabular}

${ }^{*} p$ value $<0.05$.

hence, they were included in the multivariable binary logistic regression model. However, religion, type of DM, glycemic control, physical activity, and substance use had a $p$ value of greater than 0.20 ; therefore, they were excluded from the multivariable logistic regression analysis.

Multivariable analysis indicated that male patients had 1.92 times higher odds of depression compared to female patients $(\mathrm{AOR}=1.92,95 \% \mathrm{CI}: 1.15-3.22)$. The odds of depression were 3.02 times higher among urban residents compared to rural residents $(\mathrm{AOR}=3.02,95 \% \mathrm{CI}$ : 1.57 5.78). Patients with single marital status ( $\mathrm{AOR}=7.72,95 \%$ CI: $3.60-16.53)$ and divorced or widowed $(\mathrm{AOR}=1.91,95 \%$ CI: 1.05-3.47) had higher odds of depression compared to married patients. The odds of depression among patients who had been with DM for 5 or more years were 2.05 times higher compared to patients who had been with illness for less than 5 years $(\mathrm{AOR}=2.05,95 \% \mathrm{CI}: 1.21-3.50)$. Patients who had sexual dysfunction had 3.55 times higher odds of depression than those who had no sexual dysfunction $(\mathrm{AOR}=3.55,95 \%$ CI: 2.13-5.91) (Table 3).

\section{Discussion}

This study is aimed at assessing the prevalence of depression among DM patients on follow-up at MTUTH and TGH. It was revealed that the prevalence of depression among the study participants was $37 \%$, and most (44.7\%) had mild depression. This magnitude is almost similar to the findings of studies conducted in Malaysia (40.3\%) [31], Southern India (37.5\%) [34], and Nepal (34\%) [35]. However, the finding is lower than studies conducted in Ethiopia, $43.6 \%$ [36], and Tanzania (87\%) [17]. The inconsistency between the current and former studies might be due to variation in the tools used to measure depression, sociocultural, and behavioral-related factors among study participants.

Male patients were found to be more depressed than female patients in the current study. This finding disagrees with other studies conducted among diabetic patients [18, 26]. This inconsistency could be attributed to the differences in sociocultural, gender role, and mechanisms used to cope up with the problem between males and females across study settings. For instance, males do not disclose their problems to others and worry alone. Thus, they may not get advice or other support, which helps to relieve the problem. The current study also revealed that participants who were not in a marital union (single, divorced, or widowed) were more likely to be depressed than their counterparts (married). A similar finding was reported by a study conducted in Sri Lanka [18]. A study from southern India also indicated that being unmarried increases the risk of depression [34]. Individuals in the marital union could get social and psychological support which helps them to get relieved from depression. 
Supports from a partner also improve adherence to antidiabetic medications, which in turn help to prevent DMrelated complications and associated depression. Similarly, evidence from the literature showed that social support has a protective effect against depression [37].

Urban residences were more likely to be depressed compared with rural residents in the current study. This might be due to differences in socioeconomic and environmental factors between the two settings. Urban residents suffer more to manage their lives compared to rural residents. This study also indicated that the odds of having depression increased with the duration of DM. A similar finding was reported by a study conducted in Saudi Arabia [37]. The increased risk of depression with the duration of the illness could be because longer duration of DM is associated with an increased risk of developing DM-related complications and comorbidities. The presence of sexual dysfunction was also found to be significantly associated with an increased risk of depression among diabetic patients in the current study. This finding agrees with the results of other studies [38, 39]. Likewise, other studies revealed an increased risk of sexual dysfunction among diabetic patients with depressive symptoms $[40,41]$.

4.1. Limitation. We employed a cross-sectional study design; therefore, we cannot be sure of the temporal relationship between the predictors and outcome variables.

\section{Conclusions}

The prevalence of depression among DM patients in the study was high. Therefore, we recommend that patients with DM should be thoroughly screened for this comorbid condition, and collaborative management for both depression and diabetes mellitus is necessary. Also, the odds of depression are higher among male patients, urban residents, single marital status, longer duration of DM ( $\geq 5$ years), and patients with sexual dysfunction, and they should be addressed during routine follow-up for DM for better treatment outcome.

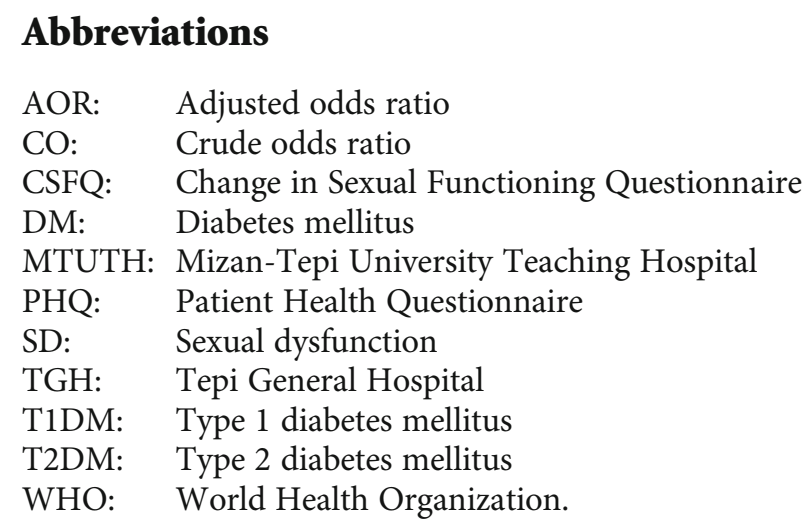

\section{Data Availability}

The data sets used and analyzed during the current study are available from the corresponding author on reasonable request.

\section{Ethical Approval}

Ethical clearance was obtained from the Institutional Review Board (IRB) of Mizan-Tepi University.

\section{Consent}

Informed written consent was also obtained from all participants after explaining the purpose of the study, the importance of their contribution, and the right to refuse participation. All information gathered was kept confidential.

\section{Conflicts of Interest}

All authors declare that they have no competing interests.

\section{Authors' Contributions}

All authors were equally involved in the conception of the study, design of the methodology, supervision of the data collection, data analysis, and interpretation of the results. The manuscript was drafted by Adane Asefa and edited by all other authors. All authors have read and approved the final manuscript for publication.

\section{Acknowledgments}

We are extremely grateful to Mizan-Tepi University for the arrangement of a conducive platform to undertake this research. We extend our thanks to the study participants and data collectors.

\section{References}

[1] L. E. Egede and C. Ellis, "Diabetes and depression: global perspectives," Diabetes Research and Clinical Practice, vol. 87, no. 3, pp. 302-312, 2010.

[2] C. E. Lloyd, A. Nouwen, N. Sartorius et al., "Prevalence and correlates of depressive disorders in people with Type 2 diabetes: results from the International Prevalence and Treatment of Diabetes and Depression (INTERPRET-DD) study, a collaborative study carried out in 14 countries," Diabetic Medicine, vol. 35, no. 6, pp. 760-769, 2018.

[3] P. Saeedi, I. Petersohn, P. Salpea et al., "Global and regional diabetes prevalence estimates for 2019 and projections for 2030 and 2045: Results from the International Diabetes Federation Diabetes Atlas, 9th edition," Diabetes Research and Clinical Practice, vol. 157, p. 107843, 2019.

[4] N. H. Cho, J. E. Shaw, S. Karuranga et al., "IDF diabetes atlas: global estimates of diabetes prevalence for 2017 and projections for 2045," Diabetes Research and Clinical Practice, vol. 138, pp. 271-281, 2018.

[5] S. Dunachie and P. Chamnan, "The double burden of diabetes and global infection in low and middle-income countries," Transactions of The Royal Society of Tropical Medicine and Hygiene, vol. 113, no. 2, pp. 56-64, 2019.

[6] H. Herrman, C. Kieling, P. Mcgorry, R. Horton, J. Sargent, and V. Patel, "Reducing the global burden of depression: a LancetWorld Psychiatric Association Commission," Lancet, vol. 393, no. 10189, pp. e42-e43, 2019. 
[7] “Depression," November,2019. https://www.who.int/newsroom/fact-sheets/detail/depression.

[8] World Health Organization Depression and Other Common Mental Disorders Global Health Estimates, 2017.

[9] G. E. Simon, "Treating depression in patients with chronic disease," The Western Journal of Medicine, vol. 175, no. 5, pp. 292-293, 2001.

[10] B. Chireh, M. Li, and C. D'Arcy, "Diabetes increases the risk of depression: a systematic review, meta-analysis and estimates of population attributable fractions based on prospective studies," Preventive Medicine Reports, vol. 14, p. 100822, 2019.

[11] S. V. Bădescu, C. Tătaru, L. Kobylinska et al., "The association between diabetes mellitus and depression," Journal of medicine and life, vol. 9, no. 2, pp. 120-125, 2016.

[12] The Lancet Diabetes \& Endocrinology, "Poor mental health in diabetes: still a neglected comorbidity," The Lancet Diabetes and Endocrinology, vol. 3, p. 393, 2015.

[13] L. C. Brown, S. R. Majumdar, S. C. Newman, and J. A. Johnson, "History of depression increases risk of type 2 diabetes in younger adults," Diabetes Care, vol. 28, no. 5, pp. 1063-1067, 2005.

[14] B. B. Gebre, S. Anand, and Z. M. Assefa, "Depression and Its Predictors among Diabetes Mellitus Patients Attending Treatment in Hawassa University Comprehensive Specialized Hospital, Southern Ethiopia," Journal of Diabetes Research, vol. 2020, 9 pages, 2020.

[15] B. A. Dachew, A. M. Birhanu, F. M. Alemu, S. A. Balcha, and T. D. Ashenafi, "Depression in diabetic patients attending University of Gondar Hospital Diabetic Clinic, Northwest Ethiopia," Diabetes, Metabolic Syndrome and Obesity Targets and Therapy, vol. 9, p. 155, 2016.

[16] B. Duko, M. Erdado, and J. Ebrahim, "Prevalence and factors associated with depression among hospital admitted patients in South Ethiopia: cross sectional study," BMC Research Notes, vol. 12, no. 1, pp. 73-74, 2019.

[17] Z. D. Khan, J. Lutale, and S. M. Moledina, "Prevalence of depression and associated factors among diabetic patients in an outpatient diabetes clinic," Psychiatry Journal, vol. 2019, Article ID 2083196, 6 pages, 2019.

[18] M. H. Arambewela, N. P. Somasundaram, H. B. P. R. Jayasekara, and M. P. Kumbukage, "Prevalence of Depression and Associated Factors among Patients with Type 2 Diabetes Attending the Diabetic Clinic at a Tertiary Care Hospital in Sri Lanka: A Descriptive Study," Psychiatry Journal, vol. 2019, Article ID 7468363, 8 pages, 2019.

[19] A. Alzahrani, A. Alghamdi, T. Alqarni, R. Alshareef, and A. Alzahrani, "Prevalence and predictors of depression, anxiety, and stress symptoms among patients with type II diabetes attending primary healthcare centers in the western region of Saudi Arabia: a cross-sectional study," International Journal of Mental Health Systems, vol. 13, no. 1, 2019.

[20] A. Pan, M. Lucas, Q. Sun et al., "Bidirectional association between depression and type 2 diabetes mellitus in women," Archives of internal medicine, vol. 170, no. 21, pp. 18841891, 2010.

[21] L. I. Berge and T. Riise, "Comorbidity between type 2 diabetes and depression in the adult population: directions of the association and its possible pathophysiological mechanisms," International Journal of Endocrinology, vol. 2015, Article ID 164760, 7 pages, 2015.
[22] X. Bai, Z. Liu, Z. Li, and D. Yan, "The association between insulin therapy and depression in patients with type 2 diabetes mellitus : a meta-analysis," BMJ Open, vol. 8, no. 11, article e020062, 2018.

[23] P. M. Trief, "Depression in elderly diabetes patients," Diabetes Spectrum, vol. 20, no. 2, pp. 71-75, 2007.

[24] E. R. Nascimento, A. E. Nardi, and A. Cardoso, "The role of depression on glycemic control," Journal of Endocrinology and Metabolism, vol. 4, no. 5-6, pp. 119-120, 2014.

[25] P. S. Ciechanowski, W. J. Katon, and J. E. Russo, "Depression and diabetes: impact of depressive symptoms on adherence, function, and costs," Archives of internal medicine, vol. 160, no. 21, pp. 3278-3285, 2000.

[26] A. K. Khuwaja, S. Lalani, R. Dhanani, I. S. Azam, G. Rafique, and F. White, "Anxiety and depression among outpatients with type 2 diabetes : a multi-centre study of prevalence and associated factors," Diabetology and Metabolic Syndrome, vol. 2, no. 1, 2010.

[27] W. J. Katon, "The comorbidity of diabetes mellitus and depression," The American Journal of Medicine, vol. 121, 11 Suppl 2, pp. S8-15, 2008.

[28] A. Camara, N. M. Baldé, S. Enoru, J. S. Bangoura, E. Sobngwi, and F. Bonnet, "Prevalence of anxiety and depression among diabetic African patients in Guinea: Association with HbA1c levels," Diabetes \& Metabolism, vol. 41, no. 1, pp. 62-68, 2015.

[29] A. Lopez-de-Andrés, M. I. Jiménez-Trujillo, V. HernándezBarrera et al., "Trends in the prevalence of depression in hospitalized patients with type 2 diabetes in Spain : analysis of hospital discharge data from 2001 to 2011," PLoS One, vol. 10, no. 2, article e0117346, 2015.

[30] K. Naicker, J. A. Johnson, J. C. Skogen et al., "Type 2 diabetes and comorbid symptoms of depression and anxiety: longitudinal associations with mortality risk," Diabetes Care, vol. 40, no. 3, pp. 352-358, 2017.

[31] K. Ganasegeran, P. Renganathan, R. A. Manaf, and S. A. R. AlDubai, "Factors associated with anxiety and depression among type 2 diabetes outpatients in Malaysia: a descriptive crosssectional single-centre study," BMJ Open, vol. 4, no. 4, article e004794, 2014.

[32] A. H. Clayton, E. L. McGarvey, and G. J. Clavet, “The Changes in Sexual Functioning Questionnaire (CSFQ): development, reliability, and validity," Psychopharmacology Bulletin, vol. 33, no. 4, pp. 731-745, 1997.

[33] M. Udedi, A. S. Muula, R. C. Stewart, and B. W. Pence, "The validity of the patient health Questionnaire-9 to screen for depression in patients with type-2 diabetes mellitus in noncommunicable diseases clinics in Malawi," BMC Psychiatry, vol. 19, no. 1, p. 81, 2019.

[34] A. S. Aminu, V. Chandrasekaran, and S. Nair, "Depression among patients with diabetes: a community-based study in South India," Journal of Medical Sciences, vol. 37, no. 6, p. 237, 2017.

[35] D. P. Pahari, R. Upadhyay, and C. K. Sharma, "Depression among diabetic patients visiting a diabetes center in Nepal," Health Prospect, vol. 17, no. 1, pp. 21-25, 2018.

[36] S. Dejene, "Depression and diabetes in Jimma University Specialized Hospital, Southwest Ethiopia," Journal of Psychiatry, vol. 17, no. 3, 2014.

[37] M. A. Salinero-Fort, P. Gómez-Campelo, F. J. S. AndrésRebollo et al., "Prevalence of depression in patients with type 
2 diabetes mellitus in Spain (the DIADEMA Study): results from the MADIABETES cohort," BMJ Open, vol. 8, no. 9, article e020768, 2018.

[38] M. Ziaei-Rad, M. Vahdaninia, and A. Montazeri, "Sexual dysfunctions in patients with diabetes: a study from Iran," Reproductive Biology and Endocrinology, vol. 8, no. 1, p. 50, 2010.

[39] W. J. Katon, "Clinical and health services relationships between major depression, depressive symptoms, and general medical illness," Biological Psychiatry., vol. 54, no. 3, pp. 216-226, 2003.

[40] G. Corona, G. Rastrelli, V. Ricca et al., "Risk factors associated with primary and secondary reduced libido in male patients with sexual dysfunction," The Journal of Sexual Medicine, vol. 10, no. 4, pp. 1074-1089, 2013.

[41] E. Bąk, C. Marcisz, S. Krzemińska, D. Dobrzyn-Matusiak, A. Foltyn, and A. Drosdzol-Cop, "Relationships of sexual dysfunction with depression and acceptance of illness in women and men with type 2 diabetes mellitus," International Journal of Environmental Research and Public Health, vol. 14, no. 9, p. 1073, 2017. 